\title{
MUSICOTERAPIA FAMILIAR SISTÊMICA: AS PRÁTICAS SONORO-MUSICAIS NO FORTALECIMENTO DOS VÍNCULOS FAMILIARES PÓS-ADOÇÃO
}

\author{
SYSTEMIC FAMILY MUSIC THERAPY: SOUND-MUSICAL PRACTICES \\ IN THE STRENGTHENING OF POST-ADOPTION FAMILY TIES
}

MUSICOTERAPIA FAMILIAR SISTÉMICA: PRÁCTICAS SONORAS MUSICALES

EN EL FORTALECIMIENTO DE LOS ENLACES FAMILIARES POST ADOPCIÓN

GABRIELY LEME GARCIA $^{1}$

LYDIO

ROBERTO SILVA ${ }^{1}$

1 Universidade Estadual do Paraná (UNESPAR),

Paranavaí/PR, Brasil

Recebido em 13/05/2020

Aprovado em 20/11/2020
RESUMO: A Musicoterapia Familiar Sistêmica (MFS) é uma abordagem pouco explorada no Brasil e tem como objetivo utilizar a música e seus elementos para promover a melhoria do sistema familiar e das relações familiares. Às vezes, as questões a serem trabalhadas na terapia familiar são complexas e difíceis de expressar em palavras e, nesse contexto, as práticas sonoro-musicais podem favorecer a expressão desses conteúdos. Nesta pesquisa tem-se como objetivo descrever as contribuições das práticas sonoromusicais no fortalecimento dos vínculos familiares pós-adoção na perspectiva da MFS. Caracteriza-se como pesquisa qualitativa e exploratória. Consiste no relato de seis intervenções realizadas com uma família pós-adoção, em Curitiba/PR. Conclui-se que as intervenções realizadas possibilitaram observar mudanças significativas na escuta e na postura dos membros da família, aspectos que contribuíram na dinâmica familiar e oportunizaram ampliar o conhecimento sobre a MFS.

Palavras-chave: Musicoterapia familiar sistêmica; Musicoterapia; Família; Adoção; Terapia familiar.

ABSTRACT: The Systemic Family Music Therapy (SFMT) is an underexplored approach in Brazil, and it aims to use music and its elements to promote the improvement of the family system and family relationships. Sometimes, the issues to be worked on in family therapy are complex and difficult to express in words and, in this context, musical practices can favor the expression of these contents. This research aims to describe the contributions of sound-musical practices in strengthening post-adoption family ties from the perspective of the SFMT. It is characterized as qualitative and exploratory research. It reports six interventions carried out with a post-adoption family, in Curitiba, Paraná, Brazil. It concludes that the interventions made it possible to observe significant changes in the listening and posture of family members, aspects that contributed to the family dynamics, as well as providing opportunities to expand the knowledge about SFMT.

Keywords: Systemic family music therapy; Music therapy; Family; Adoption; Family therapy.

RESUMEN: La Musicoterapia Familiar Sistémica (MFS) es un enfoque poco explorado en Brasil y tiene como objetivo utilizar la música y sus elementos para promover la mejora del sistema familiar y las relaciones familiares. A veces, los temas que se deben trabajar en la terapia familiar son complejos y difíciles de expresar con palabras y, las prácticas sonido-musicales pueden favorecer la expresión de estos contenidos. Esta investigación tiene como objetivo describir las contribuciones de las prácticas sonido-musicales en el fortalecimiento de los lazos familiares posteriores a la adopción en la perspectiva del MFS. Se caracteriza por la investigación cualitativa y exploratoria. Informa seis intervenciones realizadas con una familia posterior a la adopción, en Curitiba, Paraná, Brasil. Concluye que las intervenciones permitieron observar cambios significativos en la escucha y la postura de los miembros de la familia, aspectos que contribuyeron a la dinámica familiar, así como brindar oportunidades para expandir el conocimiento sobre MFS.

Palabras clave: Musicoterapia familiar sistémica; Musicoterapia; Familia; Adopción terapia familiar. 


\section{INTRODUÇÃO}

Com base nas demandas sociais e culturais dos últimos cinquenta anos, em vários países e, especificamente, no Brasil, surgiram diferentes modalidades de atendimentos terapêuticos como formas de ajudar os indivíduos e as sociedades a buscar equilíbrio emocional, físico, psíquico e social.

O surgimento dessas novas abordagens nos Estados Unidos, na Europa e na América Latina incluiu diversos grupos e pessoas envolvidas no movimento de transformação das práticas terapêuticas, em que as ideias de relação inter e intrapessoal se apresentaram como relevantes para compreender o sofrimento psíquico de grupos e de indivíduos. Nessa perspectiva, dentre os grupos que influenciaram na construção teórica da Terapia Familiar Sistêmica, é possível citar a teoria de campo de Kurt Lewin, em 1988; a ênfase de Bion no trabalho de grupos, na década de 1960; os grupos de encontro de Carl Rogers; a Gestalt-terapia como uma teoria da relação entre o todo e as partes, figura/fundo, o trabalho com grupos, e o psicodrama de Moreno, em 1921 (Féres-Carneiro, 2005).

Em processos terapêuticos na modalidade individual, é possível observar que a família influencia diretamente no processo do paciente, isto é, "as ações e comportamentos de um dos membros influenciam e simultaneamente são influenciados pelos comportamentos de todos os outros" (Lamanno, 1987, p. 17). Dessa forma, a Terapia Sistêmica Familiar compreende o grupo família como um sistema, em que cada membro do grupo pode influenciar todos os outros do sistema familiar. Além disso, em alguns casos em que o indivíduo não mais se beneficia do atendimento individual, e em que os membros da família, como pai, mãe, irmãs e irmãos também necessitam de acompanhamento terapêutico, é sugerido que frequentem atendimentos na modalidade familiar. No caso de famílias constituídas por filhas/os adotivos, o acompanhamento terapêutico no início da adoção pode contribuir para a vinculação afetiva entre mãe, pai e filhas/os, auxiliando-os com as dificuldades que possam surgir na fase inicial do processo de adoção, no decorrer da aproximação e posterior estágio de convivência. Dentre muitas práticas terapêuticas, como as psicoterapias verbais e arteterapia, a Musicoterapia pode ser uma possibilidade de atendimento para famílias.

A Musicoterapia é um campo de conhecimento que estuda e se utiliza da música, de seus elementos e experiências musicais para o desenvolvimento de um processo terapêutico na relação paciente-terapeuta. O/a musicoterapeuta é "profissional de nível superior ou especialização, com formação reconhecida pelo MEC e com registro em seu órgão de representação de categoria" (União Brasileira das Associações de Musicoterapia, 2018).

A Musicoterapia é uma área relativamente nova se comparada com outras práticas terapêuticas no Brasil, e, por se tratar de uma profissão recente, ainda há campos de atuação inexplorados, dentre eles, a Musicoterapia Familiar Sistêmica (Valentin, 2016).

\section{MUSICOTERAPIA FAMILIAR SISTÊMICA E OS PROCESSOS DE ADOÇÃO}

A Musicoterapia Familiar Sistêmica (MFS) tem por objetivo utilizar a música e seus elementos para promover a melhora do sistema familiar e das relações familiares (Valentin, 2016). Em muitos momentos, as questões a serem trabalhadas em terapia familiar são complexas e difíceis de serem expressadas em palavras, podendo a música auxiliar na expressão desses conteúdos: 
Na musicoterapia familiar sistêmica, a música é utilizada não apenas como uma forma de mobilização de emoções e sentimentos dos integrantes do grupo, mas como aquela que nutre a relação entre os membros e permite emergir a realidade simbólica daquele sistema familiar. (Valentin, 2016, p. 107)

A MFS é atualmente uma abordagem pouco explorada no Brasil; de forma geral, as publicações acerca da prática musicoterapêutica com famílias são escassas. No entanto, pesquisas desenvolvidas apresentaram resultados promissores quanto ao potencial da utilização da música como recurso terapêutico para as famílias (Valentin, Ribeiro, Conceição, \& Santos, 2015).

A prática musicoterapêutica com famílias tem a particularidade de permitir que conteúdos específicos de cada membro da família sejam expressos simultaneamente através do fazer sonoro-musical, ao contrário de outras terapias com foco na expressão verbal, em que os indivíduos se expressam individualmente, um de cada vez (Valentin, 2016).

Não foram encontradas publicações brasileiras que abordam o tema Musicoterapia e adoção, sendo este um trabalho pioneiro no Brasil.

Segundo o art. 41 do Estatuto da Criança e do Adolescente (ECA), Lei n. 8.069, de 13 de julho de 1990, "A adoção atribui a condição de filho ao adotado, com os mesmos direitos e deveres, inclusive sucessórios, desligando-o de qualquer vínculo com pais e parentes, salvo os impedimentos matrimoniais" (1990, art. 41).

As motivações para as pessoas buscarem a adoção são diversas, incluindo, segundo Weber, em pesquisa realizada com casais: o desejo de formar uma família, a necessidade de preencher a solidão, a ajuda a uma criança, o fato de proporcionar companhia para um filho único, escolher o sexo do próprio filho, infertilidade, entre outros. (1998, citado por Costa \& Campos, 2003, p. 222).

É importante ressaltar que, na maioria dos casos, a família adotiva passa por instabilidades emocionais, como medos e incertezas, por lidar com a relação com um novo membro na família, em como lidar com a história de origem da criança, além da idealização do seu perfil (Costa \& Campos, 2003, p. 225). Dentre os medos vivenciados pelos adotantes, é possível citar a dificuldade na construção de vínculo, ou até mesmo a não vinculação.

O vínculo é, neste caso, compreendido como elo entre pessoas, uma "estrutura dinâmica" (Pichon-Rivière, 1995, p. 37). Por se tratar de uma estrutura dinâmica, que necessita de constante manutenção, a confiança, a empatia e o acolhimento são aspectos de grande relevância para a construção de vínculo entre adotantes e adotados.

A situação da adoção coloca questões pessoais, existenciais e comportamentais tanto para os pais quanto para as crianças adotadas. Problemas relativos à identidade, à rejeição, à confiabilidade, a culpas e ressentimentos, atitudes antissociais, etc. são comuns nas histórias de adoção. (Reis, 2010, p. 107)

A Musicoterapia pode ser uma importante alternativa terapêutica para auxiliar nessa fase, visto que a música pode ser utilizada como um canal de expressão e comunicação, dentro de uma perspectiva lúdica e dinâmica.

A terapia pode ser de ajuda tanto durante quanto após o processo de adoção. A família precisa estar preparada para as/os filhas/os, assim também as/os filhas/ os necessitam de preparo para deixar a instituição de acolhimento e integrar uma nova família. 


\section{METODOLOGIA}

Esta pesquisa caracteriza-se como qualitativa, exploratória, e teve como objetivo descrever as contribuições das práticas sonoro-musicais no fortalecimento dos vínculos familiares pós-adoção na perspectiva da Musicoterapia Familiar Sistêmica. (Valentin, 2016)

Esta pesquisa foi submetida ao Comitê de Ética em Pesquisa com Seres Humanos (CAAE 15679219.0.0000.0094), e os participantes assinaram o termo de consentimento livre e esclarecido (TCLE).

No Brasil, existem leis e normas descritas no ECA que regulamentam o processo de adoção, objetivando a proteção integral da criança e do adolescente. Assim sendo, para efeito da autorização e legalidade das ações práticas desta pesquisa, conforme orientação do Núcleo Psicossocial da Vara da Infância e Juventude da cidade de Curitiba/PR, foi aguardada a indicação do grupo de apoio pós-adoção CHESED $^{1}$, da cidade de Curitiba/PR, das famílias disponíveis para a realização das intervenções musicoterapêuticas.

A fim de conhecer as famílias que frequentam o grupo, suas dificuldades e possíveis demandas terapêuticas, tanto dos pais, mães, quanto das filhas e filhos, e para proporcionar espaço para a identificação e vinculação com a pesquisadora, foram realizadas, previamente, observações simples (Gil, 2008) junto às famílias no grupo pós-adoção CHESED.

Para selecionar a família participante, foram realizadas entrevistas focalizadas (Gil, 2008) e preenchimento das fichas musicoterapêuticas ${ }^{2}$ com duas famílias (Barcellos, 2016). Os critérios utilizados para a escolha da família foram:

- família constituída por casal heterossexual, compreendendo que este é o perfil de adotantes que também apresentam dificuldades no processo vinculação devido às suas motivações para adotar; como já apresentado por Weber (1998), há questões dos casais adotantes, como infertilidade, necessidade de preencher solidão, e o medo referente à história do adotado anterior à institucionalização - que podem influenciar no processo de vinculação quando não há devida atenção a estas questões.

- filhas/os acima de cinco anos de idade. Por se tratar de perfis de crianças que já possuem significativa experiência em relação ao convívio com a progenitora e o progenitor - presentes aqui também experiências marcadas por negligência, maus- tratos e abuso sexual (Baptista; Soares, \& Henriques, 2013, p. 399), e ainda experiências da institucionalização. Acrescenta-se que crianças menores de cinco anos de idade, quando disponíveis para a adoção, não permanecem longo período institucionalizadas por se enquadrarem no perfil de maior busca de adotantes. (Xavier \& Olesko, 2013, p. 12)

- família constituída por até três filhas/os, levando em consideração o espaço físico disponível para a realização das intervenções.

- condição financeira que não permite o acesso a acompanhamento terapêutico para os membros da família.

- disponibilidade para participar semanalmente da pesquisa.

- queixas das mães, pais e das/os filhas/os, referentes às dificuldades na relação entre si.

- diferenças entre mãe, pai e filhas/os, reveladas durante a entrevista e preenchimento de ficha musicoterapêutica, especificamente, referentes ao aspecto sonoro-musical.

- recomendação da coordenadora do grupo de pós-adoção CHESED.
1 CHESED - Pais Por Adoção é um grupo pós-adoção na cidade de Curitiba, que tem por objetivo diminuir o número de desistências, devoluções e aumentar 0 número de casais que querem adotar.

2 Ficha musicoterapêutica é um procedimento exclusivo da Musicoterapia, que tem por objetivo conhecer o máximo possível da história sonoro-musical do paciente. Possui o caráter de anamnese, é desenvolvida para se adequar ao público atendido. (Barcellos, 2016, p. 190) É um objeto de coleta de dados pessoais do paciente/cliente e informações referentes à história sonoro-musical. Nesta ficha há informações relativas ao ambiente sonoro que 0 paciente vivenciou, canções da infância, adolescência e vida adulta, canções preferidas e também quanto ao rechaço e desagrados a sons e canções. Além de informações pertinentes à prática terapêutica, por exemplo, diagnósticos. A ficha serve para direcionar as intervenções musicoterapêuticas.

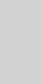


A família que foi selecionada para a pesquisa é constituída por cinco integrantes: pai, mãe, duas filhas e um filho, sendo as filhas e o filho irmãos biológicos adotados. A sentença de adoção havia sido dada há aproximadamente dois anos e meio.

Foram realizadas seis intervenções musicoterapêuticas em um Centro de atendimentos musicoterapêuticos de uma Universidade em Curitiba-PR, semanalmente, com duração de 40 a 50 minutos cada. O número de intervenções foi determinado a partir do prazo para a finalização do trabalho de conclusão de curso e os seus registros foram realizados em vídeos e na forma de relatórios descritivos.

As intervenções sonoro-musicais abrangeram propostas lúdicas, corporais, de recriação de canção, de improvisação e regência. Para tanto, as propostas tinham que ser aceitas por todos os membros da família, independente das idades e respeitando os limites individuais. Após as intervenções abria-se espaço para diálogos sobre a experiência da prática sonoro-musical mediados pela musicoterapeuta.

Para sintetizar as informações que descrevem os/as participantes da pesquisa, optou-se por apresentá-las na Tabela 1. Destaca-se que foram utilizados nomes fictícios para preservar a identidade dos/as participantes.

Tabela 1 - Perfil dos participantes da pesquisa

\begin{tabular}{|c|c|c|c|c|c|}
\hline & Mãe & Pai & Filho mais velho & Filha do meio & $\begin{array}{l}\text { Filha mais } \\
\text { nova }\end{array}$ \\
\hline Nome & Maria & Antônio & Pedro & Suzana & Lúcia \\
\hline Idade & 43 anos & 43 anos & 15 anos & 11 anos & 7 anos \\
\hline $\begin{array}{l}\text { Preferências } \\
\text { instrumentais }\end{array}$ & Harmônicos & Harmônicos & $\begin{array}{l}\text { Percussivos e de } \\
\text { sopro (bateria) }\end{array}$ & $\begin{array}{c}\text { Harmônicos e de } \\
\text { sopro } \\
\text { (flauta; piano) }\end{array}$ & $\begin{array}{c}\text { Harmônicos } \\
\text { e de sopro } \\
\text { (piano) }\end{array}$ \\
\hline $\begin{array}{l}\text { Preferências } \\
\text { musicais }\end{array}$ & $\begin{array}{l}\text { Hinos } \\
\text { religiosos }\end{array}$ & $\begin{array}{c}\text { Hinos } \\
\text { religiosos; } \\
\text { Sertanejo raiz }\end{array}$ & Funk; Rap; Trap & Funk & Rock; Funk \\
\hline $\begin{array}{l}\text { Cantoras } \\
\text { (es)/grupos/ } \\
\text { bandas }\end{array}$ & $\begin{array}{l}\text { Cantores } \\
\text { evangélicos }\end{array}$ & $\begin{array}{c}\text { Cantores } \\
\text { evangélicos; } \\
\text { Rádio Ouro } \\
\text { Verde-Paraná }\end{array}$ & $\begin{array}{l}\text { Anitta; Mc Lan; } \\
\text { Eduardo Costa }\end{array}$ & $\begin{array}{l}\text { Anitta; Mc Lan; } \\
\text { Mc Melody }\end{array}$ & $\begin{array}{l}\text { Galinha } \\
\text { Pintadinha }\end{array}$ \\
\hline $\begin{array}{c}\text { Rechaço } \\
\text { musical e } \\
\text { instrumental }\end{array}$ & $\begin{array}{c}\text { Bateria; } \\
\text { Samba; Funk; } \\
\text { Axé; Rock; } \\
\text { Eletrônica; } \\
\text { Sons altos }\end{array}$ & $\begin{array}{c}\text { Bateria; } \\
\text { Samba; Funk; } \\
\text { Axé; Rock; } \\
\text { Eletrônica }\end{array}$ & $\begin{array}{l}\text { Alguns } \\
\text { sertanejos raiz; } \\
\text { Mãe brigando }\end{array}$ & $\begin{array}{l}\text { Nenhum } \\
\text { específico }\end{array}$ & $\begin{array}{l}\text { Nenhum } \\
\text { específico }\end{array}$ \\
\hline $\begin{array}{l}\text { Ambiente } \\
\text { sonoro } \\
\text { durante a } \\
\text { infância }\end{array}$ & $\begin{array}{l}\text { Não se } \\
\text { recorda }\end{array}$ & $\begin{array}{c}\text { Sítio } \\
\text { (sons de } \\
\text { animais) }\end{array}$ & $\begin{array}{l}\text { Sons de tiro de } \\
\text { manhã e noite; } \\
\text { Sons de brigas }\end{array}$ & $\begin{array}{l}\text { Sons de tiro de } \\
\text { manhã e noite; } \\
\text { Sons de brigas }\end{array}$ & $\begin{array}{c}\text { Sons de tiro } \\
\text { de manhã e } \\
\text { noite; } \\
\text { Sons de } \\
\text { brigas }\end{array}$ \\
\hline $\begin{array}{l}\text { História } \\
\text { musical } \\
\text { familiar }\end{array}$ & $\begin{array}{l}\text { Hinos } \\
\text { religiosos }\end{array}$ & Sertanejo raiz & $\begin{array}{c}\text { Família biológica } \\
\text { ouvia funk; } \\
\text { Eduardo Costa }\end{array}$ & $\begin{array}{c}\text { Família biológica } \\
\text { ouvia funk; } \\
\text { Eduardo Costa }\end{array}$ & $\begin{array}{l}\text { Família } \\
\text { biológica } \\
\text { ouvia funk; } \\
\text { Eduardo } \\
\text { Costa }\end{array}$ \\
\hline
\end{tabular}

Fonte: Autores, 2019.

Antônio e Maria são casados há mais de 20 anos e a principal motivação para a adoção foi decorrente da infertilidade do casal, entre outros motivos. Ambos nunca estiveram em acompanhamento terapêutico. Na entrevista inicial, a mãe relatou que tinha dificuldades em demonstrar afeto, amor com as filhas e filho. O filho mais velho, Pedro, foi diagnosticado com hiperatividade. 
Como se pode observar na Tabela 1, mãe, pai e filhas/os apresentavam diferenças socioculturais e político-econômicas, principalmente, nos aspectos sonoromusicais, sobretudo, acerca de suas preferências e desagrados.

As intervenções musicoterapêuticas foram planejadas a partir das informações coletadas na entrevista inicial e preenchimento de ficha musicoterapêutica. Os instrumentos musicais utilizados nas intervenções foram: violão, bateria, piano, ovinho, metalofone, bongo, cajon, reco-reco e maracas. Foram escolhidos instrumentos melódicos, harmônicos e percussivos que permitissem a movimentação no setting e que contemplassem os interesses dos membros da família.

Como práticas sonoro-musicais, serão consideradas neste artigo todas as produções sonoras e musicais dos participantes, emergentes durante as intervenções nos atendimentos musicoterapêuticos, a partir das experiências musicais de recriação, audição, composição e improvisação (Bruscia, 2016).

A análise dos dados coletados nas intervenções musicoterapêuticas foi realizada com base na análise de conteúdo de Bardin (2011), a partir dos vídeos e dos relatórios descritivos.

\section{RESULTADOS E DISCUSSÃO}

A seguir, apresentam-se as possíveis contribuições das práticas sonoro-musicais para o fortalecimento dos vínculos familiares, considerando as dificuldades relatadas pela família na entrevista inicial e preenchimento da ficha musicoterapêutica nas intervenções, bem como o posterior feedback com a mãe, pai e filhas/o.

As contribuições foram definidas como: modificações nos padrões de relações familiares; integração entre os membros da família no fazer sonoro-musical compartilhado; oportunização de espaço-tempo para a escuta dos membros da família.

\section{Modificações nos padrões de relações familiares}

Normalmente, as pessoas possuem padrões de comportamento, de relações, de crenças que frequentemente são definidos pela cultura na qual o indivíduo está inserido, condição que lhe permite viver em grupo. Cada grupo apresenta padrões diferentes; a família é o grupo primário no processo de socialização e também possui características, padrões de relações, crenças e hábitos. Por esta razão, muitos indivíduos precisam se adaptar para serem aceitos em seus grupos. "Ao longo de seu ciclo de vida, as famílias necessitam realizar mudanças e se adaptar a novas realidades" (Valentin, 2016, p. 105); na adoção, a chegada de um novo membro ocasiona divergências nos padrões de vida das mães e pais, e é necessário que as famílias flexibilizem ou encontrem novos padrões de relacionamentos e comportamentos.

Muitas vezes, porém, é difícil para os indivíduos se adaptarem às mudanças no sistema familiar. Quando as famílias não conseguem se adaptar às novas realidades e aos novos membros na família que passam a integrá-la por meio do nascimento ou adoção, é comum ocorrerem dificuldades de relacionamento e comportamentos disfuncionais, como, por exemplo, o surgimento de sintomas e comportamentos suicidas, distúrbios alimentares, depressão, uso de drogas, entre outros (Valentin, 2016).

Nesta família existiam padrões de relacionamentos que foram observados no CHESED - grupo de pós-adoção anterior à realização das intervenções, e que posteriormente se repetiram durante as intervenções.

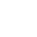


A partir da entrevista, fichas e intervenções, delineou-se que a família tinha os seguintes padrões de relacionamento: por exemplo, a filha mais nova, Lúcia, tinha mais atenção dos pais se comparada com a irmã e o irmão; isso porque Suzana permanecia em silêncio, sem muitas manifestações, e Pedro permanecia, na maioria das vezes, próximo ao pai. Pareciam estruturas cristalizadas.

A família apresentava diversas diferenças socioculturais entre seus membros, especificamente, em relação ao aspecto sonoro-musical. Isto ficou evidente em relação às preferências musicais. Observou-se, inicialmente, nas intervenções, dificuldades de aceitação e até rechaços com as escolhas musicais da mãe e do pai pelos as/o filhas/o e das/o filhas/o pelos pais.

Mãe e pai, em suas expressões musicais, evidenciaram o pertencimento ao segmento religioso cristão, no qual se observou padrões estabelecidos, como, por exemplo, como cada membro da família deve se comportar, se relacionar, o que é ou não permitido ser cantado e/ou escutado. No entanto, as/o filhas/o que foram adotados, principalmente Pedro (15 anos) e Suzana (11 anos), chegaram à família com experiências de vida que envolviam privações das necessidades básicas, dificuldades de relacionamento com os familiares, ambiente sonoro com tiros e brigas, envoltos em sons e músicas diferentes daquelas que eram permitidas na família adotante.

Sabe-se que, ao serem adotados, passariam a aprender os padrões das relações preestabelecidas pela mãe e pai, fato que ficou evidente durante a entrevista inicial. Além desse aspecto, a mãe e o pai pertenciam a um segmento religioso que não permitia contato com a música produzida fora do contexto da igreja e, por esta razão, canções populares, folclóricas e outras que não pertenciam ao hinário religioso eram consideradas profanas e não recomendadas para a audição dos membros da família. Isto é, as/o filhas/o não teriam aprovação dos pais para escutar músicas como funk e rap, bem como para estudarem instrumentos musicais percussivos, ainda que fossem aspectos importantes e que eram parte de sua identidade sonoro-musical.

Entende-se por identidade sonoro-musical as vivências sonoras gestacionais intrauterinas, e vivências do nascimento e infantis, até os dias de hoje, isto é, o contato com os sons e músicas. (Benenzon, 1988)

Nesse aspecto, as intervenções musicoterapêuticas foram planejadas visando à introdução de elementos sonoro-musicais que constituíam a identidade das/o filhas/o, da mãe e do pai, de forma que fossem trabalhadas terapeuticamente, com o objetivo de oferecer novos padrões de relação com a música, com os instrumentos musicais e entre os membros da família.

Em um setting musicoterapêutico, é possível vivenciar diferentes emoções, principalmente através da música - que se caracteriza entre tantas outras coisas, pela grande diversificação de experiências emocionais -, assim como através de situações inusitadas que ocorrem nos jogos recursivos, nos jogos de livre produção sonora e musical, os quais, muitas vezes, possibilitam a quebra de barreiras emocionais preestabelecidas ou mesmo cristalizadas. (Craveiro, 2003, p. 69)

Para tanto, os instrumentos percussivos, o funk e as músicas religiosas foram inseridos gradativamente, conforme os participantes aceitavam e interagiam sonoro-musicalmente com as propostas. Essas intervenções foram realizadas com cautela para que a mãe e o pai não sentissem uma possível transgressão com os padrões que já eram por eles conhecidos. 
Na primeira intervenção, a família não demonstrou estar em um fazer sonoromusical compartilhado; os membros interagiam com os instrumentos de forma individual, sem fazer contato visual; e não havia a atenção entre os membros da família. Eram necessárias intervenções para estruturar a produção sonoro-musical, de maneira que o violão fosse utilizado, oferecendo uma estrutura harmônica e de andamento; enquanto isso, era necessário verbalmente colocar a atenção dos membros sobre o fazer sonoro-musical.

Posteriormente, na segunda intervenção, a mãe de Pedro, que rechaçava a bateria, foi convidada pelo filho para aprender a tocar o instrumento. Maria tocou a bateria e Pedro aparentava estar animado com a participação da mãe.

Na terceira intervenção, foram levadas duas canções: um hino religioso ("Seguro Estou" - Congregação Cristã no Brasil) e um funk infantojuvenil ("Você me faz tão bem" - MC Melody e Rafinha Dragão), no qual não havia palavras que possivelmente ofendessem a moral dos pais, ambas as músicas coletadas da ficha musicoterapêutica. Foi cantado, primeiro, o hino religioso; a mãe cantou com forte intensidade e todos acompanhavam com seus instrumentos, incluindo a bateria. Foi modificado o andamento da canção, para que fosse possível introduzir outros instrumentos percussivos, como ovinhos e cajon. Em seguida, foi cantado o funk, e os pais não resistiram. Ao contrário, com os instrumentos disponíveis no setting, acompanharam as/o filhas/o, que cantavam e tocavam o funk. Neste aspecto, a canção foi introduzida buscando ressignificação, visto que, anteriormente, era compreendida pelos pais como algo desagradável.

No caso de um processo terapêutico, passar a pensar de uma outra forma sobre uma mesma música que está ligada a um fato, situação ou pessoa e que carrega uma emoção a estes ligada, pode ser a possibilidade de ressignificar estes fatos, situações ou, ainda, relações com as pessoas ligadas a essa música. (Barcellos, 2016, p. 296)

A intervenção musicoterapêutica proporcionou que as canções antes rechaçadas pela mãe e pelo pai, o funk, e o hino religioso, pelas/o filhas/o, ganhassem uma nova aparência, valorizando a identidade sonoro-musical de cada membro da família - isto é, favoreceram a modificação de padrões das relações familiares, bem como oportunizaram que os membros pudessem interagir com a identidade individual própria ao experimentarem instrumentos, tocarem e cantarem músicas antes rechaçadas. Nesse sentido, Valentin (2016, p. 108) explica que "O setting musicoterapêutico torna-se um espaço para que novos padrões de interação familiar surjam e se repitam por meio do fazer musical, até tornarem-se efetivos e se estabelecer uma estrutura nova e mais funcional para aquela família”.

Observou-se, assim, que as modificações nos padrões de relações podem favorecer o fortalecimento dos vínculos familiares, ao destacar que a família se adapta às novas realidades, descobrindo novas formas de se relacionar com os integrantes, acolhendo as experiências anteriores à adoção, suas identidades sonoro-musicais, e fazendo contato com suas histórias de vida. 
É sabido que fazer música é uma atividade antiga do ser humano. Ao longo da história humana, a música foi utilizada como forma de comunicação, expressão, rituais de cura, expressão da religiosidade, e, de forma geral, era uma atividade que oportunizava o encontro de pessoas. Além disso, os sons e a música estão presentes na vida das pessoas desde a fase intrauterina; estão presentes também no desenvolvimento infantil até a vida a adulta.

Em Musicoterapia, o fazer sonoro-musical compartilhado, que envolve tocar e cantar conjuntamente, pode favorecer a construção de relações de empatia e confiança, oportunizando, assim, a vinculação:

Quando cantamos a mesma música juntos, vivemos na mesma melodia, compartilhamos o mesmo centro tonal, articulamos a mesma letra, nos movemos no mesmo ritmo - momento a momento, som a som, por uma contínua consciência do outro e através de esforços contínuos de permanecer juntos e então tornar-se uno com a experiência. (Bruscia, 2016, p. 87)

Na primeira e segunda intervenções, a família não apresentava unidade musical; tocavam individualmente. Alguns membros, como Pedro e Lúcia, com mais intensidade. É compreendida neste trabalho a interação diferente de integração. Quanto ao ato de interagir, a família interagia musicalmente, ao tocar uns com os outros. Contudo, não estava integrada, não havia um movimento de troca sonoro-musical, sinergia, escuta ou acolhimento daquilo que os membros produziam no setting.

$\mathrm{Na}$ quinta intervenção, Suzana aparentava estar brava com uma situação ocorrida na manhã daquele dia, demonstrava ciúmes da irmã Lúcia. Ao iniciar as propostas, a família demonstrou, por meio da produção sonoro-musical, não haver conexão; não havia um fazer sonoro-musical compartilhado, nem escuta dos outros membros, isto é, havia uma dissonância musical, assim como havia uma dissonância no sistema familiar. Foi necessário estruturar ritmicamente e harmonicamente a produção sonoro-musical da família, visto que, naquele dia, a família não conseguia se organizar sozinha. Ao final da intervenção, a situação entre as irmãs foi mediada verbalmente, juntamente com a mãe e o pai.

No feedback com as/o filhas/o, após as seis intervenções, Pedro relatou que aquele momento das intervenções - isto é, 50 minutos semanalmente - era um dos únicos em que a família se reunia, estava envolvida em uma mesma atividade, nesse caso, tocando, cantando e experimentando novas possibilidades.

Dessa forma, as intervenções musicoterapêuticas favoreceram a integração entre os membros da família. "A música ajuda a aprofundar as relações familiares, favorecendo a reciprocidade, a confiança e novos insights sobre os relacionamentos, o que torna as atitudes mais positivas entre os envolvidos" (Valentin, 2016, p. 109). Em outras palavras, a dinâmica dos encontros oportunizou um espaço para a reunião da família, no qual foi possível compartilhar experiências num fazer sonoro-musical compartilhado, integrando os membros da família e, por conseguinte, fortalecendo os vínculos familiares. 
O setting musicoterapêutico é um espaço acolhedor, de confiança e empatia, mediado por uma/um musicoterapeuta, que tem como objetivo trabalhar sobre as necessidades de seus pacientes. Foi possível observar que as dinâmicas do fazer sonoro-musical naquele tempo-espaço no setting musicoterapêutico, de certa forma, reproduziam as dinâmicas daquele sistema familiar. Neste aspecto, evidenciavam como os membros da família se relacionavam. Por exemplo: Lúcia, a todo momento, solicitava a atenção dos pais, e obtinha essa atenção; Suzana se expressava pouco, falava pouco e apresentava comportamento mais contido. Essas eram dinâmicas evidenciadas no fazer sonoro-musical.

A produção musical constitui-se em uma metáfora do funcionamento familiar: a escolha dos instrumentos musicais, como cada pessoa segura e toca os instrumentos, os sons produzidos, tudo isso fornece informações sobre os padrões interacionais da família em questão - papéis, alianças, fronteiras, disputas de poder, entre outros. (Valentin, 2016, p. 108)

Nas primeiras intervenções, a filha mais nova, Lúcia, buscava a atenção dos pais a todo o momento. Fazia isso quando tocava com forte intensidade e se recusava a participar das propostas que colocavam a irmã e o irmão em evidência. Nas intervenções cinco e seis, Lúcia começou a participar mais das propostas, principalmente, em comparação com as primeiras intervenções, pois permitia que os outros membros da família tocassem e, também, alertava quando um deles era esquecido (propositalmente) ao tocar e cantar.

Para que haja comunicação, é necessário que haja uma escuta. Nas intervenções um e dois, os membros da família tocavam todos ao mesmo tempo, porém, desconexos e, principalmente as/o filhas/o, com forte intensidade. Não havia um tempo de espera, nem de escuta sobre aquilo que os outros estavam cantando ou tocando, sendo necessário direcionar as intervenções visando à possibilidade de que todos os membros pudessem tocar/cantar e serem escutados.

Dessa forma, foram feitas intervenções com a finalidade de ampliar a comunicação entre os membros da família, de maneira que pudessem falar, cantar, tocar e serem escutados - principalmente Suzana, que se expressava menos, se comparada com a mãe, pai, irmã e irmão.

O processo musicoterapêutico permitiu a ampliação de canais de comunicação para além do verbal. Observou-se que, por vezes, é difícil para os pacientes falarem sobre suas dificuldades e sofrimentos e, assim sendo, a produção sonoro-musical pode ocupar um lugar de comunicação, no qual pacientes podem se expressar através do fazer sonoro-musical.

A MFS promove um "momento em que crianças e adolescentes conseguem compartilhar uma atividade sem ficarem agressivas ou estressadas, escutando a si mesmas e sendo executadas por seus familiares" (Valentin, 2016, p. 108). Foi possível, nas intervenções, que as/o filhas/o se expressassem sem que houvesse censura por parte da mãe e do pai sobre o que era permitido cantar e tocar. As identidades sonoras-musicais puderam ser ouvidas, bem como se oportunizou que mãe e pai fossem escutados pelas/o filhas/o, em um espaço lúdico, onde era permitido explorar e se expressar. Uma das estratégias utilizadas para oportunizar que os membros da família pudessem tocar, cantar e serem ouvidos foi a "condução", definida por Bruscia (2016) como uma das variações dos métodos recriacionais.

Nova Perspectiva Sistêmica, v. 29, n. 68, p. 6-18, dezembro 2020. 
Condução é quando "O cliente dirige ao vivo uma performance musical fornecendo dicas gestuais aos músicos como ditado por uma partitura ou outra notação" (Bruscia, 2016, p. 130).

$\mathrm{Na}$ intervenção quatro, em que foi realizada a proposta de condução, todos os membros da família estavam em instrumentos. Pedro na bateria, Antônio no Bongo, Maria no cajon, Suzana no violão, Lúcia ao piano. Individualmente, cada membro da família se dirigiu até o centro da sala e corporalmente conduzia a produção sonora. Levantar o braço correspondia a tocar mais forte; baixar os braços, tocar mais fraco; e balançar as mãos, a acelerar o andamento. Todos passaram pela experiência de ir até o centro e conduzir, enquanto os outros tinham a atenção na pessoa no centro da sala, acompanhando os movimentos e simultaneamente acompanhando a produção da família.

Essas intervenções possibilitaram que os membros da família pudessem ser escutados, considerando que as dinâmicas no fazer sonoro-musical reproduziam as dinâmicas do sistema familiar. Ao oportunizar que os membros se escutassem, que colocassem em evidência todos os membros da família, infere-se que, possivelmente, se reproduziu e se vivenciou estas novas dinâmicas do sistema familiar presente, em outros espaços. Portanto, ao ampliar a comunicação entre seus membros e oportunizar que todos pudessem falar, tocar, cantar e serem escutados, se configuravam momentos de evidência em como essas contribuições podiam fortalecer os vínculos familiares.

Posteriormente às seis intervenções foi realizado feedback com mãe, pai, filhas/o. Segundo as/o filhas/o, aqueles dias foram importantes para reunir a família, ver a mãe e pai tocando, além de terem diminuído as brigas em casa. A mãe e o pai relataram que as filhas e o filho eram diferentes nas intervenções de como eram em casa, agitados.

Esse feedback trouxe à tona o diagnóstico de hiperatividade de Pedro, o qual não parecia adequado, pois conforme observado nas intervenções, Pedro participava ativamente, respeitando o tempo de cada membro da família, ouvindo e permitindose ser ouvido, com atenção nas propostas. Contudo, em casa, Pedro manifestava comportamentos que evidenciam o diagnóstico de hiperatividade, como agitação, descrita pela mãe.

A mudança de comportamento de Pedro afetou toda a família nas intervenções, ao oportunizar que todos pudessem estar atentos e vê-lo como uma pessoa além do diagnóstico de hiperatividade. O setting musicoterapêutico se tornou um espaço para a reunião de todos os membros da família, principalmente, ao levar em conta a idade das/o filhas/o, suas demandas individuais (que não foram abordadas nas intervenções) e suas identidades sonoro-musicais.

\section{CONSIDERAÇÕES FINAIS}

Pelo que fora observado, a Musicoterapia pode ser um caminho para auxiliar famílias no processo de vinculação. Futuramente, pretende-se realizar pesquisas que incluam também famílias monoparentais e homossexuais, visto que há poucas pesquisas quanto a estes formatos de família, e trata-se de um campo a ser explorado e discutido.

Esta é uma pesquisa pioneira no campo da Musicoterapia no Brasil e para futuras pesquisas a metodologia possivelmente sofrerá alterações, visto que a Musicoterapia Familiar Sistêmica e a Musicoterapia no âmbito da adoção são áreas em desenvolvimento e ampliação no Brasil.

Nova Perspectiva Sistêmica, v. 29, n. 68, p. 6-18, dezembro 2020. 
Durante as intervenções, ocorreram demandas individuais dos membros da família, da mãe, do pai e das/o filhas/o. Recomendou-se à família que continuasse com os atendimentos musicoterapêuticos na modalidade individual, e possivelmente mantivesse $o$ atendimento mensal a toda a família.

As possíveis contribuições das práticas sonoro-musicais no fortalecimento dos vínculos familiares no processo pós-adoção foram definidas como: modificações nos padrões de relações familiares; integração entre os membros da família no fazer sonoro-musical compartilhado; oportunização de espaço-tempo para a escuta dos membros da família. A condução interpretativa das intervenções ficou centrada nas proposições teóricas de Valentim (2016), uma vez que a autora discorre e fundamenta a abordagem da MFS.

Como benefícios, a construção de tal conhecimento pode contribuir para o campo teórico e prático da Musicoterapia, pois a difusão da abordagem da Musicoterapia Familiar Sistêmica pode se tornar um conduto com maior visibilidade, principalmente ao ampliar espaços de atuação ao musicoterapeuta, além de proporcionar uma nova visão para a prática musicoterapêutica.

\section{REFERÊNCIAS}

Baptista, J., Soares, I., \& Henriques, M. (2013). Recuperação Desenvolvimental Após a Adoção: Características da Criança e da Família Adotiva. Psicologia: Reflexão e Crítica, 26(2), 396-404. Recuperado de https://www.redalyc.org/ pdf/188/18827804020.pdf

Barcellos, L. R. M. (2016). Quaternos de Musicoterapia e Coda. Dallas, TX: Barcelona Publishers.

Bardin, L. (2011). Análise de conteúdo. São Paulo: Edições 70.

Benenzon, R. (1988). Teoria da Musicoterapia. São Paulo: Summus.

Bruscia, K. E. (2016). Definindo Musicoterapia (3a ed., M. Leopoldino, trad.). Dallas, TX: Barcelona Publishers.

Costa, L. F. \& Campos, N. M. V. (2003). A avaliação psicossocial no contexto da adoção: Vivências das famílias adotantes. Psicologia: Teoria e Pesquisa, 19(3), 221-230.

Craveiro, L. C. S. (2003). A teia do tempo e o autista: Música e musicoterapia. Goiânia: Ed. UFG.

Féres-Carneiro, T. (2005). Articulando diferentes enfoques teóricos na terapia familiar. Revista Interamericana de Psicología, 39(3), 439-448. Recuperado de http://psicorip.presser.net.br/Resumos/PerP/RIP/RIP036a0/RIP03951.pdf

Gil, A. C. (2008). Métodos e técnicas de pesquisa social (6 ${ }^{\mathrm{a}}$ ed.). São Paulo: Atlas.

Lamanno, V. L. C. (1987). Terapia familiar e de casal: Introdução às abordagens sistêmica e psicanalítica. São Paulo: Summus.

Lei n. 8.069, de 13 de julho de 1990. (1990). Dispõe sobre o Estatuto da Criança e do Adolescente e dá outras providências. Diário Oficial [da] República Federativa do Brasil. Brasília, DF. Recuperado de http://www.planalto.gov.br/ccivil_03/ LEIS/L8069.htm\#art266

Pichon-Rivière, E. (1995). Teoria do vínculo (5a ed.). São Paulo: Martins Fontes.

Reis, R. M. A. (2010). A atitude antissocial de crianças adotadas como um caso particular de reação à deprivação. Dissertação de Mestrado, Programa de Pós-graduação em Psicologia, Pontifícia Universidade Católica de Campinas, São Paulo, SP.

União Brasilleira das Associações de Musicoterapia. (2018). Definição Brasileira de Musicoterapia. Recuperado de http://ubammusicoterapia.com.br/ definicao-brasileira-de-musicoterapia/ 
Valentin, F (2016). Musicoterapia Familiar Sistêmica: O Grupo Multifamiliar como método de intervenção. In K. A. M. Barreto Motta, \& D. B. Munari (Org.), As trilhas do trabalho de grupos: Teorias e aplicabilidade (pp. 103-116). Curitiba: CRV.

Valentin, F., Ribeiro, M. K. A.s Conceição, M. I. G. \& SantoS, A. P. G. (2015). Música e Musicoterapia com famílias: Uma revisão sistemática. Revista Brasileira de Musicoterapia, 17(18), 25-42. Recuperado de http://www.revistademusicoterapia. mus.br/wp-content/uploads/2016/08/2-M\%C3\%9ASICA-E-MUSICOTERAPIA -COM-FAM\%C3\%8DLIAS.pdf

Weber, L. N. D. (1998). Laços de ternura: pesquisas e histórias de adoção. Curitiba: Santa Mônica.

Xavier, P. M. \& Olesko, M. A. (2013) Teoria versus prática: a realidade da adoção perante a Vara da Infância e Juventude do Município de Curitiba. In XXII Encontro Nacional do CONPEDI/ UNICURITIBA. Recuperado de http://www.publicadireito.com. br/artigos $/$ cod $=614 \mathrm{~d} 37 \mathrm{f} 84 \mathrm{c} 3 \mathrm{f} 41 \mathrm{a} 6$

\section{GABRIELY LEME GARCIA}

Musicoterapeuta (CPMT 347/20-PR) graduada pela Universidade Estadual do Paraná. Gestalt-terapeuta pelo Instituto de Gestalt de Curitiba. Pós-graduanda em Transtornos Neurocognitivos pela Faculdade Unyleya.

https://orcid.org/0000-0003-3507-3915

E-mail: gabriely.l.garcia@gmail.com

\section{LYDIO ROBERTO SILVA}

Mestre em Mídia e Conhecimento pela Universidade Federal de Santa Catarina. Graduado em Musicoterapia e Licenciado em Música pela Faculdade de Educação Musical do Paraná (FEMP). Docente do Bacharelado em Musicoterapia da Universidade Estadual do Paraná. https://orcid.org/0000-0002-2750-6576

E-mail: lydioroberto@gmail.com 